\title{
Establishment of the Psychometric Properties of a Disaster Resilience Measuring Tool for Healthcare Rescuers in China: A Cross-Sectional Study
}

\author{
Xiaorong Mao ${ }^{1,2,3} \cdot$ Kang $\mathrm{Chen}^{4} \cdot$ Xiuying $\mathrm{Hu}^{5} \cdot$ Xianxiu Wen $^{1} \cdot$ Alice Yuen Loke $^{2}$
}

Accepted: 17 March 2021 / Published online: 12 April 2021

(C) The Author(s) 2021

\begin{abstract}
The aim of this study was to test the validity and reliability of a tool for measuring the disaster resilience of healthcare disaster rescuers. A cross-sectional study involving 936 healthcare disaster rescuers of the Sichuan Disaster Response Team was conducted to establish the psychometric properties of the disaster resilience measuring tool (DRMT). Item analysis, exploratory factor analysis, confirmatory factor analysis, and correlation analysis were adopted to analyze the data. Item analysis showed that all but three items had the critical ratio over 3 , which indicates adequate discriminability for inclusion in the measuring tool. The exploratory factor analysis showed that $65.93 \%$ of the total variance was explained by four factors-self-efficacy, social support, positive growth, and altruism. The confirmatory factor analysis showed goodness of fit for the four-factor model: CMIN/DF (2.846), GFI $(0.916 \geq 0.90)$, CFI $(0.949 \geq 0.90)$, AGFI $(0.891 \geq$
\end{abstract}

Alice Yuen Loke

alice.yuen.loke@polyu.edu.hk

1 Department of Nursing, Sichuan Provincial People's Hospital, University of Electronic Science and Technology of China, Chengdu 610072, China

2 School of Nursing, The Hong Kong Polytechnic University, Hong Kong, China

3 Disaster Management and Reconstruction, Sichuan University-Hong Kong Polytechnic University, Chengdu 610225, China

4 National and Sichuan Provincial Emergency Medical Rescue Team, Sichuan Provincial People's Hospital, University of Electronic Science and Technology of China, Chengdu 610072, China

5 Innovation Center of Nursing Research, School of Medicine/ West China Hospital, Sichuan University, Chengdu 610041, West China, China
$0.80)$, and RMSEA $(0.063 \leq 0.08)$. Criterion validity demonstrated significant associations of the DRMT and the Connor-Davidson Resilience Scale $(P<0.01, r=0.566)$. Convergent validity was established by correlation with stress $(P<0.05, r=-0.095)$, depression $(P<0.01, r=$ - 0.127), posttraumatic stress disorder-PCL-C $(P<0.05, \mathrm{r}$ $=-0.100)$, compassion satisfaction $(P<0.01, r=0.536)$, and burnout $(P<0.01, r=-0.330)$. The DRMT demonstrated adequate internal consistency (Cronbach's alpha $>0.84$ ) and stability over the two-week study period (intraclass correlation coefficient $>0.85$ ), and a cut-off point of 61 was suggested. The disaster resilience measuring tool has satisfactory psychometric properties and is a valid, reliable, and valuable instrument for assessing disaster resilience in healthcare rescue workers. The scale needs to be tested further among other populations and those from other cultures.

Keywords China $\cdot$ Disaster resilience measuring tool $\cdot$ Healthcare rescuers $\cdot$ Factor analysis · Psychometrics

\section{Introduction}

Healthcare professionals, including physicians, nurses, and other medical staff, face various stressors in their healthcare work environments (Arrogante and Aparicio-Zaldivar 2017; Malik et al. 2020). Those involved in disaster rescue activities are particularly vulnerable when they have to deal with victims and survivors under the more challenging traumatic situations than those encountered in their work place (Stein et al. 2010). Healthcare rescuers, the healthcare professionals who were deployed to disaster rescue sites, are at higher risk of suffering from mental health 
disorders in the face of disaster rescue activities (Mao et al. 2018; Mao et al. 2019). As a result, their work effectiveness and performance are negatively affected (Moss et al. 2016), and this directly impacts the care received by victims and survivors. These healthcare rescue workers are also likely to have a low quality of life (Tang et al. 2015).

It has been proposed that individuals who are resilient are better able to overcome stressful conditions in life (Masten 2001). They are known to have better health and well-being both physically and psychologically (Resnick et al. 2011). The evidence suggests that disaster rescue workers who are resilient perform better at rescue work and are better able to return to their previous work after deployment to disaster rescue sites (Nishi et al. 2016). Managers of disaster response teams should recruit rescuers with a high level of disaster resilience (Burton 2015).

The term resilience is used widely in the fields of physics, psychology, and social sciences. The concept of resilience is receiving increasing attention in the field of disaster research and has been applied to individual, family, community, national, and regional aspects (Bonanno et al. 2010; Pendall et al. 2010; Cutter et al. 2013). In the World Conference on Disaster Reduction (WCDR) in 2005, the United Nations International Strategy for Disaster Reduction (UNISDR) was put forward to build the resilience of nations and communities to disasters, and the Hyogo Framework for Action 2005-2015 was adopted. The importance of disaster resilience was again addressed in the Sendai Framework for Disaster Risk Reduction 2015-2030 (UNISDR 2015) and in the Global Platform Preparatory Days / World Reconstruction Conference (UNDRR 2019).

Disaster resilience is regarded as the adaptive, absorptive, and transformative capacity of an individual or society to cope with disastrous events (Sarker et al. 2020). It has been reported that disaster healthcare rescuers who have a high level of resilience are less likely to suffer from negative psychological problems (McEntire 2014; Mao et al. 2018). Rather than a static individual trait, resilience is a characteristic that can be learned and promoted through enhancement programs (Reyes et al. 2015). Thus, a measurement of disaster resilience is of critical importance in assessing the effectiveness of programs aimed at enhancing resilience among rescue workers.

A variety of resilience scales has been developed in the context of disaster (Cai et al. 2018). However, almost all of these measurements have focused on the community level of disaster resilience and not the individual level. A scoping review of resilience scales of adults found that two measurements have been adopted to assess resilience among disaster healthcare rescue workers at the individual level (Mao, Wang, et al. 2020)-the Connor-Davidson Resilience Scale (Connor and Davidson 2003) and the
Resilience Scale (Wagnild and Young 1993). However, the two scales were developed among patients with psychiatric disorders and senior citizens, respectively, rather than among healthcare rescue workers in disasters. Given that resilience is a context-dependent trait (Ali-Abadi et al. 2020), the two scales were not considered appropriate for the application to healthcare rescue workers in the context of disasters. It is essential to develop a specific scale to measure the resilience of healthcare rescue workers in the context of disasters.

To address this need, the research team developed a prototype tool for measuring the disaster resilience of healthcare rescue workers by conducting a series of studies. The process began with an extensive review of the literature on the characteristics of resilience among disaster rescue workers (Mao, Fung, et al. 2020), and a focus group interview study on the views of healthcare rescuers who have been deployed to disaster rescue work on disaster resilience (Mao et al. 2019). A scoping review of resilience scales for adults was conducted, and the results of the two previous studies were incorporated, to develop a prototype disaster resilience tool for healthcare rescuers (Mao, Wang, et al. 2020). The prototype tool then underwent two rounds of modified Delphi expert survey in proposing the measurement tool (Mao, Loke, et al. 2020). In this modified Delphi study, the 66 items of the prototype measuring tool for healthcare rescue workers were refined into a disaster resilience measuring tool (DRMT) consisting of 27 items under eight domains - optimism, altruism, preparations for disaster rescue, social support, perceived control, self-efficacy, coping strategies, and positive growth-with excellent content validity (Mao, Loke, et al. 2020). However, the psychometric properties of the disaster resilience measuring tool have yet to be tested.

The purpose of this cross-sectional study was to test the disaster resilience measuring tool for reliability and validity, to establish the psychometric properties of the instrument before its use. With the establishment of the psychometric properties of the DRMT, the scale can then be used to assess the level of disaster resilience of healthcare rescuers, or to assess the effectiveness of interventions that aim to enhance the disaster resilience of healthcare rescuers.

\section{Methods}

The cross-sectional survey was conducted among registered disaster healthcare rescuers in Sichuan Province, China, in May and June 2019, and included doctors, nurses, and other medical staff. Those who were willing to participate in this study were asked to complete a questionnaire that included their demographic information, the 
refined disaster resilience measuring tool, and other relevant scales for testing the reliability and validity of the instrument.

The refined disaster resilience measuring tool emerged from the modified Delphi survey of 22 international experts in the field of disaster and was originally developed in English. This version was translated into Mandarin Chinese and then translated back into English by language professionals. Two healthcare experts in disaster, who were proficient in both English and Chinese, were then invited to review the forward and back translations of the scale. Finally, an expert in the development of measuring tool, who was proficient in both languages, was invited to examine the semantic equivalence of the original English version, the translated Chinese version, and the retranslated English version. The expert rated each item on a 3-point scale with 3 = "exactly the same meaning," 2 = "almost the same meaning," and 1 = "different meaning" (Flaherty et al. 1988). Further modifications required were made.

\subsection{Sample and Sample Size Calculation}

The participants were recruited by purposive sampling. The determination of the sample size for this cross-sectional study took into account the statistical tests to be employed for establishing the criterion-related validity, convergent validity, construct validity, and reliability (internal consistency, test-retest reliability) of the DRMT. Before analyzing the validity and reliability of the overall scale, it is necessary to carry out an item analysis to assess item discrimination and homogeneity. It has been suggested that at least 200-300 participants are required for item analysis (Ferketich 1991).

For a factor analysis to establish the construct validity of a measuring tool, a sample size estimate of 100 is considered poor, 200 fair, 300 good, 500 very good, and 1000 or more is considered excellent (MacCallum et al. 1999). A sample size of 200 or greater is considered adequate to remove the possibility of bias in a factor analysis (Curran et al. 1996).

The criterion-related validity and convergent validity of the measuring tool was evaluated using correlation analysis. The minimum required sample size was determined through an analysis of statistical power. For a statistical analysis, with a power of $80 \%$ and a medium effect size $=$ 0.20 (Liu 2013), it is determined that the minimum sample required is 52 .

The reliability of a measuring tool is determined by evaluating its internal consistency and test-retest reliability (DeVellis 2017). To calculate the intraclass correlation coefficient (ICC) for a scale with four or five Likert points, the sample size should be at least 50 (Javali et al. 2011). When the smallest possible value of 0.7 for the ICC is considered, a minimum sample size of 10 is required (Shoukri et al. 2004). If the drop-out rate is set at $20 \%$ (Bujang and Baharum 2017), the sample size for determining test-retest reliability should be increased to 13 (that is, $10 / 0.8=13$ ).

Therefore, it is expected that a minimum of 300 disaster healthcare rescuers should be recruited to establish the psychometric properties of the refined disaster resilience measuring tool (DRMT).

\subsection{Criteria for the Inclusion and Exclusion of Disaster Healthcare Rescue Workers}

The targeted participants were the healthcare rescue workers who registered with the Office of Emergency Response, in Sichuan, China. The office, under the Health Commission of Sichuan Province, is a Public Health Emergency Command Center responsible for the deployment of rescue workers in response to health/public emergency and disaster events. The target participants in this study were those who had been deployed to disaster rescue sites, and were willing to complete the questionnaire. Those who had been diagnosed with anxiety neurosis, melancholia, or a mental illness, with suicidal or homicidal intentions, or suffered from serious physical health problems from previous deployment, and who no longer had the ability to serve as disaster healthcare rescue workers, were excluded.

\subsection{The Measuring Instruments}

The measuring instrument consists of six parts. The first part solicits information on the demographic background of the participants. The second is the Chinese version of the refined disaster resilience measuring tool (DRMT-C). The third consists of the Connor-Davidson Resilience Scale (CD-RISC), the fourth the Post-Traumatic Stress Disorder Scale, the fifth the Depression Anxiety Stress Scales (DASS), and the sixth is the Professional Quality of Life Scale. The estimated amount of time required to complete the questionnaire was about 20 to 30 minutes. These measuring instruments were included for the testing of the validity of the DRMT.

In Part 1, demographic information-such as gender, age, marital status, level of education, profession, work department, and religious beliefs-was collected on the healthcare rescuers.

Part 2 is the refined tool for measuring disaster resilience (DRMT-C) that was validated for content by the experts in the modified Delphi study and on which a consensus has been achieved. This tool consists of 27 items categorized under eight domains. 
The scales in Parts 3 to 6 were included for the evaluation of the criterion and convergent validity of the refined DRMT. Part 3 is the short version of the Connor-Davidson Resilience Scale (CD-RISC, 10 items) (Campbell-Sills and Stein 2007), which was employed in related studies to measure the ability of rescue workers to cope with adversity. The respondents were asked to rate each item on a scale from 0 (not true at all) to 4 (true nearly all the time). The 10-item CD-RISC in this study displayed excellent psychometric properties, with a Cronbach's alpha of 0.95 .

Part 4 is the Post-Traumatic Stress Disorder (PTSD) Checklist Civilian Version (PCL-C), which has been used to assess PTSD among healthcare rescuers. The checklist is a self-reported 17-item symptom scale that corresponds to the American Psychiatric Association's DSM-IV criteria. Each item is scored from 1 (not at all) to 5 (extremely). Possible scores for the scale range from 17 to 85 . A person with a score of 50 or greater is classified as probably having PTSD (Perrin et al. 2007). The internal consistency of the full scale measured using the Cronbach's alpha coefficient in this study was 0.97 . The Cronbach's alpha values for the three domains were $0.93,0.95$, and 0.94 for intrusion and re-experiencing, avoidance and numbing, and hyperarousal, respectively.

Part 5 is the short version of the Depression Anxiety Stress Scales (DASS) (Henry and Crawford 2005). The DASS is a self-reported scale designed to measure the negative emotional states of depression, anxiety, and stress, with seven items in each of the three subscales. The subjects were asked to use 4-point severity/frequency scales to rate the extent to which they experienced each state over the past week. Scores were calculated by summing the scores of the items in the subcategories (Henry and Crawford 2005). The reliabilities (internal consistencies) of the DASS in this study were regarded as excellent, with the Cronbach's alpha of 0.97 for the total scale, 0.92 for the depression subscale, 0.92 for the anxiety subscale, and 0.89 for the stress subscale.

Part 6 is the Professional Quality of Life Scale (PQLS). The PQLS is a 30-item scale consisting of three facetscompassion satisfaction (CS), burnout (BO), and secondary trauma. The participants were asked to use a 5-point Likert scale to indicate their responses to each item, with $1=$ never, $2=$ rarely, $3=$ sometimes, $4=$ often, and $5=$ very often (Stamm 2009). The reliability of the PQLS in this study is considered acceptable, with Cronbach's alpha of 0.8 for the total scale and of $0.89,0.79$, and 0.89 for the subscales for compassion satisfaction, burnout, and secondary traumatic stress.

\subsection{Data Collection Procedure}

WeChat is the most commonly used Internet-based social networking software system in China's mainland. The Director of the Office of Emergency Response in Sichuan Province assisted in the process of collecting data for this study by helping to recruit the participants through this Internet social networking system.

The Director first provided a brief description of the study and its aims to the members of the emergency response team in their $\mathrm{WeChat}$ group, and briefly introduced the researcher. The information sheet, consent form, and the questionnaire, including the DRMT-C were sent to the WeChat group with 30 group leaders of healthcare rescuers. The group leaders then relayed the information to the 30-80 healthcare members in their respective rescue teams, with a total of 1190 rescuers. The participants were asked to approach the researcher directly by individual e-mail if they had any questions about the survey, rather than through the WeChat group. They were also instructed not to share their answers to the questionnaire with other team members. Finally, a total of 958 (response rate of $80.5 \%$ ) healthcare rescuers returned the questionnaire, of which 936 questionnaires were valid and included in this study.

The time interval for the evaluation of the test-retest reliability of the DRMT was considered carefully. It was important that the interval neither be too long nor too short. The appropriate time interval would vary depending on the research task, but 2-14 days is common and considered appropriate (Streiner et al. 2015). For the test and retest reliability testing, 27 participants were invited to repeat the DRMT scale 14 days after they first completed the questionnaire.

\subsection{Data Analysis}

All data were downloaded for analysis from the online survey platform Wenjuanxing - an automatic questionnaire system in China-into the Statistical Package for Social Science (SPSS) Version 25 for Windows and AMOS SPSS. Both descriptive and inferential statistical methods were adopted.

Descriptive statistics, including frequencies, percentages, means, and standard deviations, were used to describe the characteristics (for example, age, gender, marital status) of the participants. All of the procedures for validating the disaster resilience measuring tool are outlined in Fig. 1.

The item analysis was conducted by evaluating the item discriminability and item homogeneity. The critical ratio (CR) was used to determine whether an item had sufficient discriminative power. Each item between the $27 \%$ highestscoring group and the $27 \%$ lowest-scoring group was 
Fig. 1 The process of the validation of the disaster resilience measuring tool (DRMT-C)

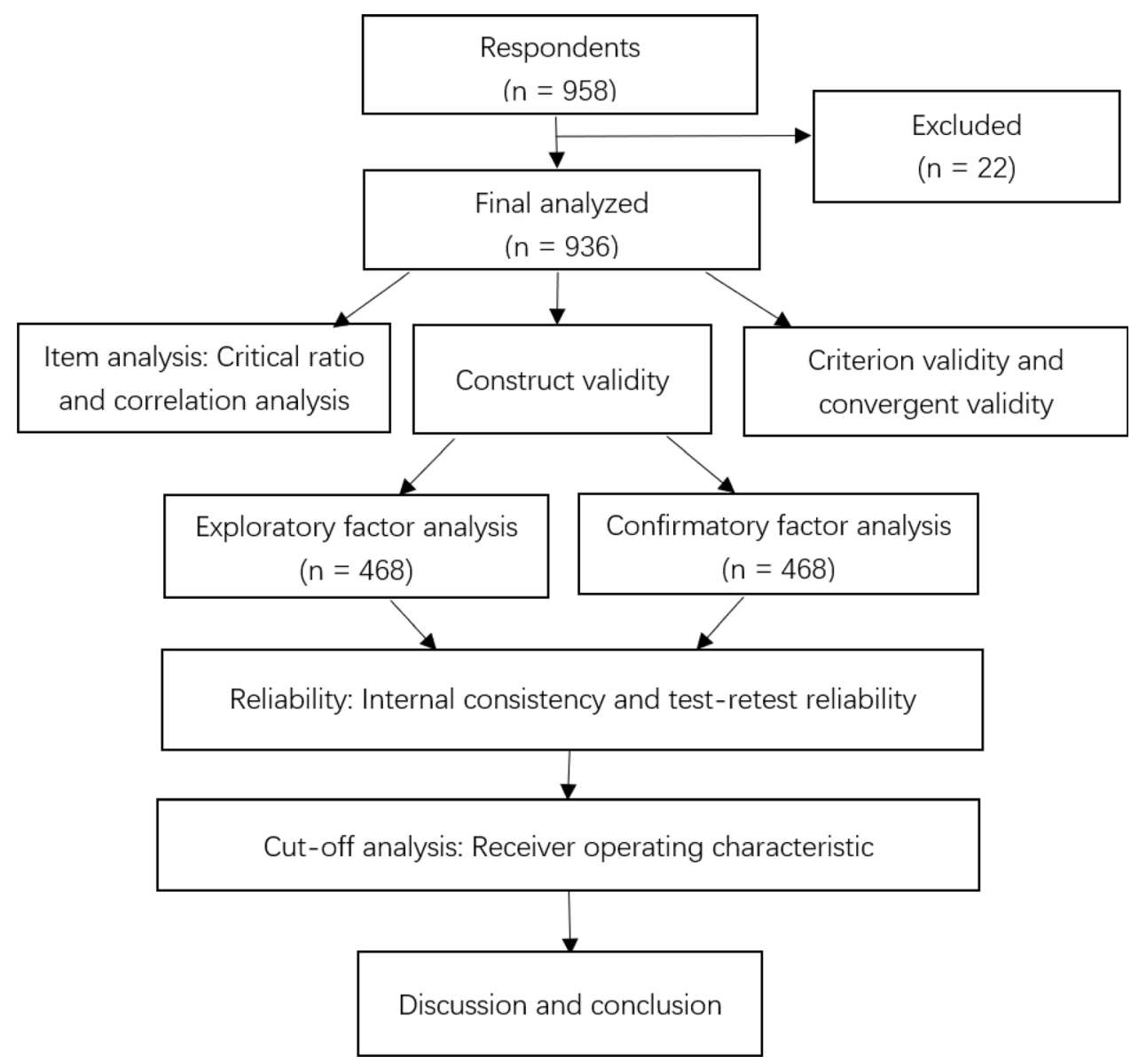

assessed using a two independent-sample $t$-test, with a CR value of more than 3 indicating good item discriminability. A correlation analysis was conducted to examine the homogeneity between the items and the entire test. Items with a CR value of below 3 or a correlation coefficient of below 0.3 were eliminated (Field 2013).

An exploratory factor analysis (EFA) and a confirmatory factor analysis (CFA) were conducted to determine the construct validity of the DRMT-C. The correlation analysis was conducted to assess the criterion-related validity and convergent validity of the measuring tool. The level of significance for the statistical tests was set at $p \leq 0.05$. Items with factor loadings of above 0.40 (Tsai et al. 2015) were considered for inclusion in the final measuring tool.

The reliability of the refined DRMT-C was estimated by its internal consistency, measured by Cronbach's alpha (Javali et al. 2011), and by its test-retest reliability, measured by the ICC obtained in the test-retest method (Streiner et al. 2015). The significant value for reliability was set at 0.70 (Nunnally 1978; Ferketich 1991).

A receiver operating characteristic (ROC) analysis (Martin et al. 2006) was carried out to determine the optimal cut-off score when using the DRMT-C for distinguishing between high and low levels of disaster resilience in the healthcare rescuers. The levels of disaster resilience can be used to identify those who might be at risk of developing negative psychological consequences.

\section{Results}

The following section describes the demographic characteristics of the participants, the item analysis, and the validity and reliability of the refined DRMT-C.

\subsection{Characteristics of the Participants}

A total of 936 valid questionnaires returned by disaster healthcare rescue workers were included for analysis. As the numbers of the participants has a strong sample power for the analysis of EFA and CFA in subgroups (Kyriazos 2018), the questionnaires were randomly assigned to EFA and CFA subgroups for analysis, with 468 subsamples in each group. The characteristics of the participants in the EFA and CFA groups are shown in Table 1. There were no significant differences between the two groups in their demographic characteristics. 
Table 1 Characteristics of the participants $(N=936)$ in the 2019 study on the disaster resilience of healthcare rescue workers in Sichuan Province, China

\begin{tabular}{|c|c|c|c|c|c|c|}
\hline \multirow[t]{2}{*}{ Characteristics } & \multicolumn{2}{|c|}{ EFA Group $(n=468)$} & \multicolumn{2}{|c|}{ CFA Group $(n=468)$} & \multirow[t]{2}{*}{$\chi^{2} / \mathrm{t}$} & \multirow[t]{2}{*}{$P$} \\
\hline & $\mathrm{N}(\mathrm{M})$ & $\%(\mathrm{SD})$ & $\mathrm{N}(\mathrm{M})$ & $\%(\mathrm{SD})$ & & \\
\hline \multicolumn{7}{|l|}{ Gender } \\
\hline Male & 95 & $20.3 \%$ & 104 & $22.2 \%$ & \multirow[t]{2}{*}{0.517} & \multirow[t]{2}{*}{0.472} \\
\hline Female & 373 & $79.7 \%$ & 364 & $77.8 \%$ & & \\
\hline Age & 39.0 & 7.8 & 38.2 & 8.6 & 1.43 & 0.153 \\
\hline \multicolumn{7}{|l|}{ Marital status } \\
\hline Single & 39 & $8.3 \%$ & 56 & $11.9 \%$ & \multirow[t]{2}{*}{3.386} & \multirow[t]{2}{*}{0.066} \\
\hline Married & 429 & $91.7 \%$ & 416 & $88.9 \%$ & & \\
\hline \multicolumn{7}{|l|}{ Education levels } \\
\hline Bachelor and below & 428 & $91.5 \%$ & 420 & $89.7 \%$ & \multirow[t]{2}{*}{0.37} & \multirow[t]{2}{*}{0.803} \\
\hline Master's and above & 40 & $8.5 \%$ & 48 & $10.3 \%$ & & \\
\hline \multicolumn{7}{|l|}{ Profession } \\
\hline Physician & 61 & $13.0 \%$ & 55 & $11.8 \%$ & \multirow[t]{3}{*}{0.908} & \multirow[t]{3}{*}{0.636} \\
\hline Nurse & 376 & $80.3 \%$ & 387 & $82.7 \%$ & & \\
\hline Emergency personnel & 31 & $6.6 \%$ & 26 & $5.6 \%$ & & \\
\hline \multicolumn{7}{|l|}{ Work department } \\
\hline Emergency department & 194 & $41.5 \%$ & 180 & $38.5 \%$ & \multirow[t]{3}{*}{1.766} & \multirow[t]{3}{*}{0.414} \\
\hline Intensive care unit & 44 & $9.4 \%$ & 51 & $10.9 \%$ & & \\
\hline Others & 230 & $49.2 \%$ & 237 & $50.6 \%$ & & \\
\hline Duration of employment & 17.78 & $8.9 \%$ & 16.91 & $9.3 \%$ & 1.47 & 0.141 \\
\hline Religious belief & 65 & $13.9 \%$ & 51 & $10.9 \%$ & 1.929 & 0.165 \\
\hline Received training on disaster & 332 & $70.9 \%$ & 354 & $75.6 \%$ & 2.642 & 0.104 \\
\hline \multicolumn{7}{|l|}{ Type of disaster rescue involved } \\
\hline Earthquake & 176 & $61.3 \%$ & 172 & $57.7 \%$ & \multirow[t]{4}{*}{2.68} & \multirow[t]{4}{*}{0.44} \\
\hline Infectious disease outbreak & 37 & $12.9 \%$ & 47 & $15.8 \%$ & & \\
\hline Traffic accidents & 51 & $17.8 \%$ & 46 & $15.4 \%$ & & \\
\hline Others & 43 & $15.0 \%$ & 33 & $11.1 \%$ & & \\
\hline \multicolumn{7}{|l|}{ Time of arrival in disaster areas } \\
\hline Within 3 days & 115 & $88.5 \%$ & 104 & $80.6 \%$ & \multirow[t]{4}{*}{3.245} & \multirow[t]{4}{*}{0.355} \\
\hline $3-7$ days & 7 & $5.4 \%$ & 10 & $7.8 \%$ & & \\
\hline $8-14$ days & 5 & $3.9 \%$ & 10 & $7.8 \%$ & & \\
\hline After 14 days & 3 & $2.3 \%$ & 5 & $3.9 \%$ & & \\
\hline Exposure to human remains & 37 & $28.5 \%$ & 31 & $24.0 \%$ & 0.656 & 0.418 \\
\hline Commander of the team & 30 & $23.1 \%$ & 23 & $17.8 \%$ & 1.095 & 0.295 \\
\hline Received counseling support after deployment & 39 & $30.0 \%$ & 27 & $20.9 \%$ & 2.805 & 0.094 \\
\hline
\end{tabular}

Note: EFA, exploratory factor analysis; CFA, confirmatory factor analysis.

\subsection{Item Analysis}

The item analysis showed that most of the items of the disaster resilience measuring tool could discriminate between those with higher and lower levels of disaster resilience (critical ratio, CR of most items was $>3$, except items \# 1, 10, and 22 with CR at 1 or 2). The correlation coefficients of the items and the whole questionnaire were higher than 0.3 , indicating the good homogeneity of the refined DRMT-C.

\subsection{Validity}

The validity of the refined DRMT-C in this study was evaluated through construct validity, which was analyzed by exploratory factor analysis and confirmatory factor 
analysis, and criterion-related validity and convergent validity.

\subsubsection{Exploratory Factor Analysis for Construct Validity}

With regard to the EFA, the Kaiser-Meyer-Olkin (KMO) statistic was first used to determine how suitable the data were for a factor analysis, and Bartlett's test of sphericity was conducted to assess whether the items could be used to detect structure. The KMO of this study at 0.942 was greater than 0.5, and Bartlett's test of sphericity was significant $\left(\chi^{2}=6285.541, P<0.001\right)$, indicating that a factor analysis would be suitable for use in evaluating the disaster resilience measuring tool.

A scree plot of the eigenvalues of factors or principal components was used to determine the number of factors to retain in an EFA or the principal components to keep in a principal component analysis (Fig. 2). The scree plot confirmed the viability of the four-factor model of disaster resilience after the removal of items $2,3,7,18$, and 21 with factor loadings below 0.40 .

The principal axis factor analysis is shown in Table 2 . The first factor (Self-efficacy) explained $20.89 \%$ of the variance with seven items, with an eigenvalue of 8.23. The second factor (Social support) explained $15.93 \%$ of the variance with four items, with an eigenvalue of 2.10 . The third factor (Positive growth) explained $15.72 \%$ of the variance with five items, with an eigenvalue of 1.20 . The fourth factor (Altruism) explained $13.39 \%$ of the variance with five items, with an eigenvalue of 1.01. In total, the four factors explained $65.93 \%$ of the cumulative variance. All of the items that remained in this model demonstrated a salient factor loading (above 0.40) on their latent variable, indicating that the disaster resilience measuring tool has a good construct structure.

\subsubsection{Confirmatory Factor Analysis for Construct Validity}

The EFA-derived four-factor solution was validated in the CFA group, as shown in Fig. 3. This CFA model shows that all regression weights exhibited a positive and significant value (above 0.4 ). The CFA indicated a highly satisfactory goodness fit for the four-factor model: minimum discrepancy (CMIN/DF, 2.846), goodness of fit index (GFI, $0.916 \geq 0.90$ ), comparative fit index (CFI, $0.949 \geq 0.90$ ), adjusted goodness of fit index (AGFI, $0.891 \geq 0.80$ ), and root mean square error of approximation (RMSEA, 0.063 $\leq 0.08)$.

\subsubsection{Criterion-Related Validity and Convergent Validity}

Criterion validity and convergent validity were analyzed using the bivariate correlations with Spearman coefficient $r$ (Table 3). The criterion-related validity of disaster resilience was evaluated using its significant relationship with the Connor-Davidson Resilience Scale (CD-RISC) $(P<$
Fig. 2 Scree plot of the principal axis factor analysis of the disaster resilience measuring tool (DRMT-C)

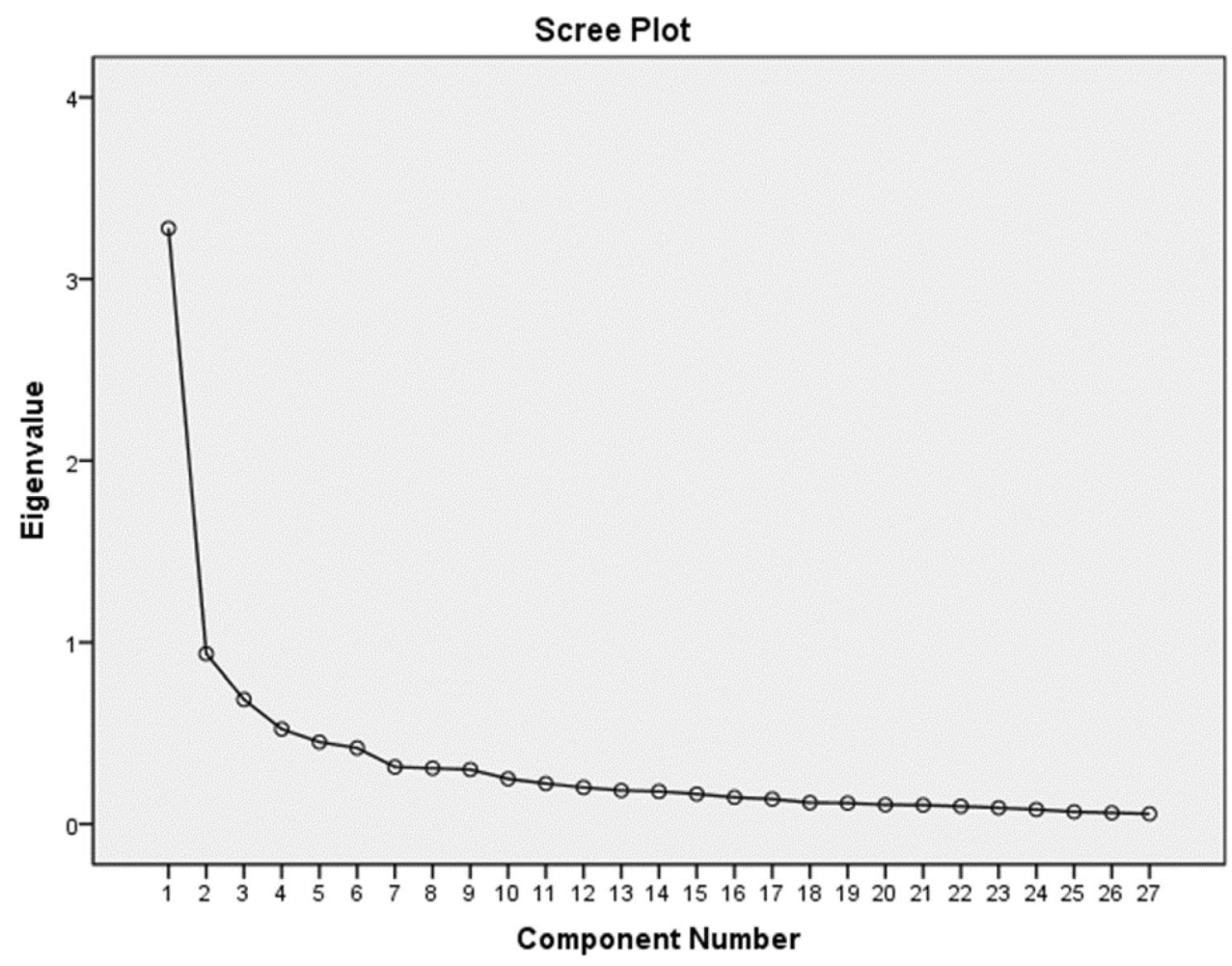


Table 2 Factor loadings of items of the disaster resilience measuring tool (DRMT-C)

\begin{tabular}{|c|c|c|c|c|c|c|c|}
\hline \multirow[t]{2}{*}{ Factors } & \multirow[t]{2}{*}{ Items } & \multicolumn{2}{|c|}{ Rotated Sums of Squared Loadings } & \multicolumn{4}{|c|}{ Rotated Component Matrix $(\alpha)$} \\
\hline & & Variance $\%$ & Cumulative $\%$ & Factor 1 & Factor 2 & Factor 3 & Factor 4 \\
\hline \multirow[t]{7}{*}{ Self-efficacy } & 16 & 20.89 & 20.89 & 0.81 & & & \\
\hline & 19 & & & 0.79 & & & \\
\hline & 8 & & & 0.72 & & & \\
\hline & 20 & & & 0.72 & & & \\
\hline & 15 & & & 0.66 & & & \\
\hline & 17 & & & 0.62 & & & \\
\hline & 9 & & & 0.57 & & & \\
\hline \multirow[t]{4}{*}{ Social support } & 11 & 15.93 & 36.82 & & 0.75 & & \\
\hline & 14 & & & & 0.72 & & \\
\hline & 13 & & & & 0.71 & & \\
\hline & 12 & & & & 0.70 & & \\
\hline \multirow[t]{5}{*}{ Positive growth } & 26 & 15.72 & 52.54 & & & 0.76 & \\
\hline & 25 & & & & & 0.75 & \\
\hline & 24 & & & & & 0.68 & \\
\hline & 23 & & & & & 0.61 & \\
\hline & 27 & & & & & 0.59 & \\
\hline \multirow[t]{3}{*}{ Altruism } & 4 & 13.39 & 65.93 & & & & 0.83 \\
\hline & 5 & & & & & & 0.83 \\
\hline & 6 & & & & & & 0.77 \\
\hline
\end{tabular}

$0.01, r=0.566)$. The convergent validity was estimated using its correlation with stress $(P<0.05, r=-0.095)$, depression $(P<0.01, r=-0.127)$, post-traumatic stress disorder (PCL-C) $(P<0.05, r=-0.100)$, compassion satisfaction $(P<0.01, r=0.536)$, and burnout $(P<0.01$, $r=-0.330)$. However, no significant association was found between disaster resilience and anxiety $(P>0.05$, $r=-0.081)$, and the secondary trauma scales $(P>0.05, r=$ $-0.028)$.

\subsection{Reliability}

The reliability of the scale was tested using Cronbach's alpha. The Cronbach's alpha for the whole disaster resilience measuring tool was 0.92 , with four factors ranging from 0.84 to 0.87 , suggesting that the disaster resilience measuring tool (DRMT-C) has satisfactory internal consistency in relation to the population of healthcare rescue workers in China. The intraclass correlation coefficient (ICC) of the scale among the 27 healthcare rescuers were all higher than 0.85 (ranging from 0.85 to 0.95 ), indicating that the disaster resilience measuring tool has adequate stability.

\subsection{Cut-off Score for Discriminating between Levels of Disaster Resilience}

The cut-off scores for the disaster resilience of healthcare rescuers and the effectiveness of the CD-RISC, CS, and BO are 59.50, 60.50, and 58.50, with a maximum Youden Index score of from 0.28 to 0.50 to discriminate between disaster healthcare rescuers with different levels of compassion satisfaction, burnout, and depression.

\section{Discussion}

The aim of this study was to evaluate the psychometric properties of a disaster resilience measuring tool (DRMTC) developed by the research team based on a series of studies (Mao et al. 2019; Mao, Fung, et al. 2020; Mao, Loke, et al. 2020; Mao, Wang, et al. 2020), and according to the guidelines on the development of scales (DeVellis 2017). The ultimate aim of establishing the psychometric properties of the measuring instrument was to measure disaster resilience in healthcare rescuers. This is the first measuring tool developed specifically for the assessment of disaster resilience of healthcare rescue workers.

The results of the item analysis showed that all but three items had adequate discriminability $(\mathrm{CR}>3)$ for inclusion 


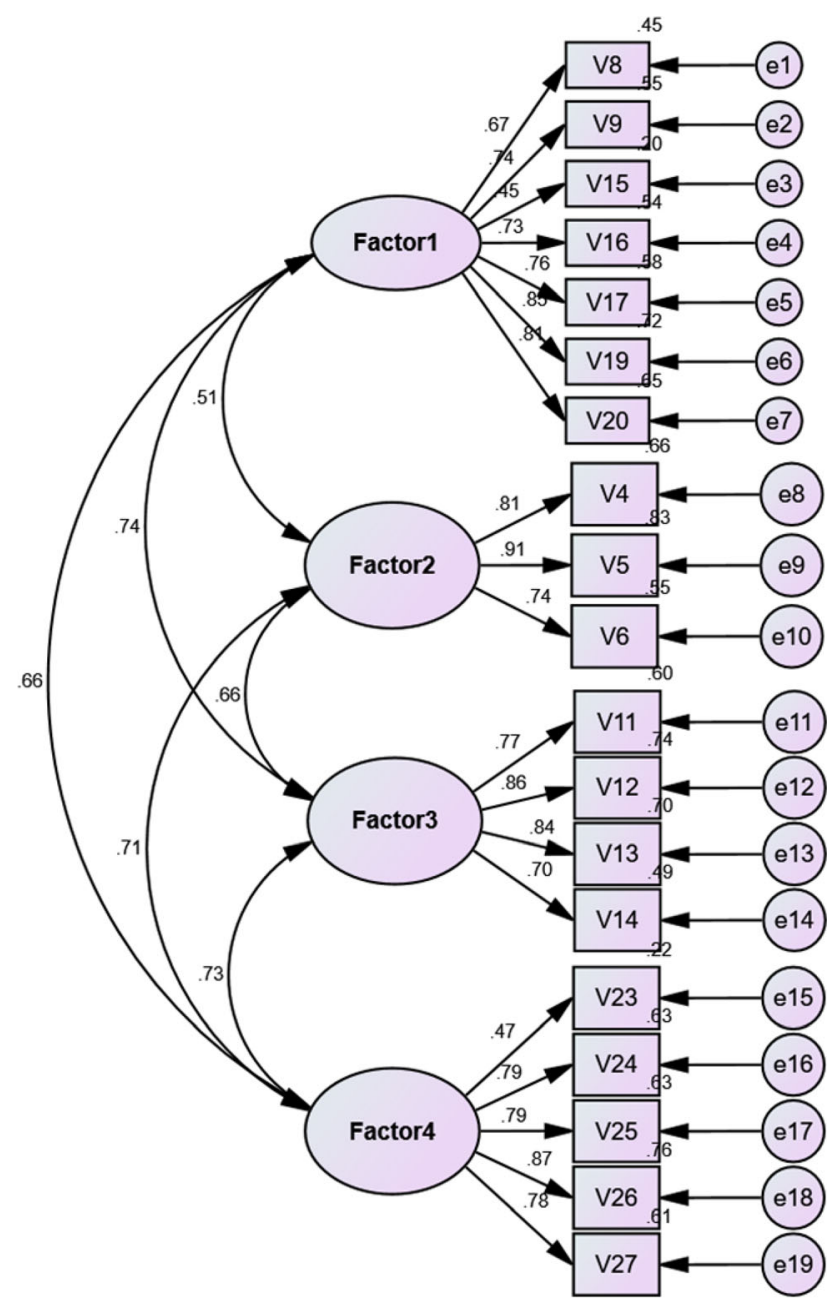

Fig. 3 Confirmatory factor analysis model of the disaster resilience measuring tool (DRMT-C) in the measuring tool. Three items \# 1, 10, and 22 with CR $<3$ were removed accordingly. Construct validity of the DRMT-C was tested by EFA and CFA. Exploratory factor analysis confirmed four factors that adequately explained $65.93 \%$ of the total variance. Items \# 2, 3, 7, 18, and 21 with factor loadings below 0.40 were removed after EFA. Confirmatory factor analysis showed a highly satisfactory goodness fit, consistent with the four-factor model. The DRMT-C also displayed good criterion-related validity, convergent validity, and excellent reliability. Finally, a four-factor DRMT-C-including the domains of self-efficacy, social support, positive growth, and altruism-with a total of 19 items was confirmed.

The resulting four-factor model supported the findings of our qualitative interview study on the views of disaster among healthcare rescuers (Mao et al. 2019), and of a review of the literature on the characteristics of resilience (Mao, Fung, et al. 2020). However, four domains-optimism, preparations for disaster, perceived control, and coping strategies - that emerged in our modified Delphi study (Mao, Loke, et al. 2020) were not supported in this study and were removed accordingly.

However, some of the items under the removed domains were grouped with the four identified factors in this study. For example, the original items \# 8, 9, 15, and 16 that were under the domains of preparations for disaster and perceived control were shifted to the domain of self-efficacy in the current study. It can be explained that both the domains of preparations for disaster and perceived control have influence and impact on an individual's self-efficacy (Jungki 2019; Kiliç and Şimşek 2019). Item 23 was originally under the domain of coping strategies and was

Table 3 Bivariate correlations, Spearman coefficient $r$ for disaster resilience, CD-RISC, DASS-21, PCL-C, and PQLS

\begin{tabular}{|c|c|c|c|c|c|c|c|c|}
\hline \multirow[t]{2}{*}{ Dimension } & \multirow[t]{2}{*}{ CD-RISC } & \multicolumn{3}{|l|}{ DASS-21 } & \multirow[b]{2}{*}{ PCL-C } & \multicolumn{3}{|l|}{ PQLS } \\
\hline & & Stress & Anxiety & Depression & & CS & BO & STS \\
\hline Disaster resilience & $0.566^{* *}$ & $-0.095^{*}$ & -0.081 & $-0.127 * *$ & $-0.100 *$ & $0.536^{* *}$ & $-0.330 * *$ & -0.028 \\
\hline CD-RISC & & $-0.154 * *$ & $-0.136^{* *}$ & $-0.178 * *$ & $-0.205^{* *}$ & $0.584 * *$ & $-0.453 * *$ & -0.039 \\
\hline Stress & & & $0.832 * *$ & $0.842 * *$ & $0.746 * *$ & $-0.132 * *$ & $0.504 * *$ & $0.591 * *$ \\
\hline Anxiety & & & & $0.875 * *$ & $0.775 * *$ & $-0.177 * *$ & $0.522 * *$ & $0.631 * *$ \\
\hline Depression & & & & & $0.765 * *$ & $-0.216^{* *}$ & $0.565 * *$ & $0.613 * *$ \\
\hline PTSD & & & & & & $-0.159 * *$ & $0.574 * *$ & $0.682 * *$ \\
\hline $\mathrm{CS}$ & & & & & & & $-0.574 * *$ & -0.044 \\
\hline BO & & & & & & & & $0.619 * *$ \\
\hline
\end{tabular}

Note: $* *=P<0.01 ; *=P<0.05$; CD-RISC, Connor-Davidson Resilience Scale; DASS-21, Depression Anxiety Stress Scales; PTSD-PCL-C, Post-Traumatic Stress Disorder Checklist Civilian Version; PQLS, Professional Quality of Life Scale; CS, Compassion Satisfaction; BO, Burnout; STS, Secondary Trauma Scales. 
shifted to the factor of social support. This may be explained by the positive relationship between social support and coping strategies (Chao 2017). The domain of optimism was also deleted, but this may be accounted for by the evidence that optimism is a predictor of positive growth (Britton et al. 2019). The items under the domain of optimism may be well reflected by positive growth, a factor that is included in this study. As such, the DRMT-C has satisfactory construct validity in a sample of Chinese healthcare rescuers on the individual level of disaster resilience.

The CD-RISC-10 was used to test the criterion-related validity of the DRMT-C on measuring psychological resilience. There was a moderate and significant correlation between the two instruments $(P<0.01, r=0.566)$, indicating a good criterion-related validity of the DRMT-C.

The PCL-C, DASS-21, and PQLS were adopted to test the convergent validity of the DRMT-C in this study. The results of the study showed that there were significant negative correlations between disaster resilience and PTSD, stress, depression, and burnout. The findings are consistent with other studies that explored the relationship between individual resilience and psychological well-being among disaster rescue workers (Johnson et al. 2011; Bensimon 2012; Zerach et al. 2013; De La Rosa et al. 2016; Scuri et al. 2019). The results supported the view that individuals who are resilient are better able to overcome stressful conditions in life (Masten 2001), and this may reduce the possibility that these healthcare rescue workers suffer from negative psychological consequences.

It was unexpected for the researchers to find that disaster resilience was negatively correlated with anxiety and secondary trauma, although with no statistical significance. This finding is different from a study conducted among military personnel and veterans (King et al. 2006). An explanation may be that healthcare rescue workers in this study who had been extensively involved in disaster rescue work, experienced positive growth following traumatic exposure, and with high levels of disaster resilience were less likely to experience anxiety (Nishi et al. 2016; Iwasa et al. 2019; Mao et al. 2019; Tominaga et al. 2020). Further study is necessary to explore the association of anxiety (and other mental health outcomes) and disaster resilience and possible changes over time.

Cronbach's alpha and ICCs were used for estimating the reliability of the DRMT-C. The Cronbach's alpha of all items in the tool are $>0.84$, well over the recommended score of 0.7 (DeVellis 2017), indicating an excellent internal consistency. In addition, the ICC values of the scale indicating the test-retest reliability were higher than 0.85 , suggestive of the reliable and stable performance of the DRMT-C.
The cut-off discriminative point of the disaster resilience measuring tool, between 58.5 and 60.5 , differentiated high and low levels of disaster resilience. This suggests that managers and researchers in the disaster field should identify those healthcare rescuers with a disaster resilience score below 61 using the DRMT and provide them with specific training to enhance disaster resilience.

The findings from the current study provide healthcare rescuers with a theoretical understanding of individual disaster resilience. The four factors of disaster resilience confirmed in this study can be considered as protective factors of rescue workers who are facing the challenges and difficulties in their deployment to disaster work. These factors demonstrated that healthcare rescuers with internal (self-efficacy, positive growth, altruism) and external (social support) resources would be less likely to suffer from negative psychological consequences following disastrous events.

As there was no specific tool that measured disaster resilience previously, studies in the area had to borrow resilience tools that were developed among populations/clients other than healthcare rescuers. These resilience tools do not consist of the two domains of disaster resilience identified in this study: positive growth and altruism. These two domains of disaster resilience were important in disaster healthcare rescuers, playing essential roles in "bouncing back," and unselfish service to others, while adapting to adverse events (Mao et al. 2019; Mao, Fung, et al. 2020). These two unique domains in the concept of disaster resilience highlighted the importance of healthcare rescuer resilience during and after deployment.

\section{Conclusion}

This study provided evidence that the disaster resilience measuring tool (DRMT-C19) with four factors has satisfactory psychometric properties and is a valid, reliable, and valuable instrument for assessing disaster resilience in Chinese healthcare rescue workers. The scale needs to be tested further among other populations and those from other cultures.

The following limitations in this study should be considered. First, purposive sampling may lead to a biased sample, as only those with motivation completed the questionnaires. Second, the recruitment of the participants and completion of the questionnaire were conducted through the WeChat social network, and only those with access to this network were able to take part. Finally, due to time limitations, the predictive validity of the disaster resilience measuring tool was not explored in this study, and should be examined in future research. 
This disaster resilience measuring tool was developed mostly in Asian countries, and validated among Chinese healthcare rescuers. The tool should also be tested for psychometric properties if it is to be used among other populations and people of different countries/cultures. Longitudinal studies of those who have been exposed to disasters, as well as those who have not, will reveal the sensitivity of this disaster resilience tool in identifying changes in disaster resilience over time. In the recruitment and training of disaster rescuers, this tool may also be used to identify individuals who may be at risk of developing negative psychological well-being.

A resilience enhancement program should be developed specifically for healthcare rescuers that covers the four domains (factors) confirmed in the disaster resilience measuring tool to facilitate their resilience. The contents of this program should be multidimensional, including disaster preparation at the individual and family level, theoretical knowledge of disasters, medical rescue skills, psychological first aid (PFA), both for victims and the rescue workers, and coping strategies to enhance the healthcare disaster rescuers' self-efficacy. Enhancement programs should also strengthen the social support of healthcare rescuers by encouraging them to seek support from others such as co-workers, professional psychologists, and friends or family members. By improving self-efficacy, gaining social support, together with a strong will to serve/ help others in need, this intervention will promote positive growth, and thus resilience among disaster rescue workers.

Acknowledgments We are grateful to the Director of the Office of Emergency Response in Sichuan Province who assisted in the process of collecting data for this research. Also, we would like to express our gratitude to all the personnel who participated in this study. Finally, we deeply thank those who helped us forward and back translate the DRMT into Chinese and English, and the experts who reviewed the translated version of the DRMT before data collection for this study.

Open Access This article is licensed under a Creative Commons Attribution 4.0 International License, which permits use, sharing, adaptation, distribution and reproduction in any medium or format, as long as you give appropriate credit to the original author(s) and the source, provide a link to the Creative Commons licence, and indicate if changes were made. The images or other third party material in this article are included in the article's Creative Commons licence, unless indicated otherwise in a credit line to the material. If material is not included in the article's Creative Commons licence and your intended use is not permitted by statutory regulation or exceeds the permitted use, you will need to obtain permission directly from the copyright holder. To view a copy of this licence, visit http://creativecommons. org/licenses/by/4.0/.

\section{References}

Ali-Abadi, T., S. Talepasand, C. Boyle, and H.S. Nia. 2020. Psychometric properties of the Baruth Protective Factors
Inventory among nursing students. PLOS ONE 15(6): Article $\mathrm{e} 0233760$.

Arrogante, O., and E. Aparicio-Zaldivar. 2017. Burnout and health among critical care professionals: The mediational role of resilience. Intensive and Critical Care Nursing 42: 110-115.

Bensimon, M. 2012. Elaboration on the association between trauma, PTSD and posttraumatic growth: The role of trait resilience. Personality and Individual Differences 52(7): 782-787.

Bonanno, G.A., C.R. Brewin, K. Kaniasty, and A.M. La Greca. 2010. Weighing the costs of disaster: Consequences, risks, and resilience in individuals, families, and communities. Psychological Science in the Public Interest: A Journal of the American Psychological Society 11(1): 1-49.

Britton, M., L. LaLonde, A. Oshio, and K. Taku. 2019. Relationships among optimism, pessimism, and posttraumatic growth in the US and Japan: Focusing on varying patterns of perceived stressfulness. Personality and Individual Differences 151: Article 109513.

Bujang, M.A., and N. Baharum. 2017. A simplified guide to determination of sample size requirements for estimating the value of intraclass correlation coefficient: A review. Archives of Orofacial Science 12(1): 1-11.

Burton, C.G. 2015. A validation of metrics for community resilience to natural hazards and disasters using the recovery from Hurricane Katrina as a case study. Annals of the Association of American Geographers 105(1): 67-86.

Cai, H., N.S.N. Lam, Y. Qiang, L. Zou, R.M. Correll, and V. Mihunov. 2018. A synthesis of disaster resilience measurement methods and indices. International Journal of Disaster Risk Reduction 31: 844-855.

Campbell-Sills, L., and M.B. Stein. 2007. Psychometric analysis and refinement of the Connor-Davidson Resilience Scale (CDRISC): Validation of a 10-item measure of resilience. Journal of Traumatic Stress: Official Publication of The International Society for Traumatic Stress Studies 20(6): 1019-1028.

Chao, S.-F. 2017. Social support, coping strategies and their correlations with older adults' relocation adjustments after natural disaster. Geriatrics \& Gerontology International 17(6): 1006-1014.

Connor, K., and J. Davidson. 2003. Development of a new resilience scale: The Connor-Davidson Resilience Scale (CD-RISC). Depression and Anxiety 18(2): 76-82.

Curran, P.J., S.G. West, and J.F. Finch. 1996. The robustness of test statistics to nonnormality and specification error in confirmatory factor analysis. Psychological Methods 1(1): 16-29.

Cutter, S.L., J.A. Ahearn, B. Amadei, P. Crawford, E.A. Eide, G.E. Galloway, M.F. Goodchild, and H.C. Kunreuther et al. 2013. Disaster resilience: A national imperative. Environment 55(2): 25-29.

De La Rosa, G.M., J.A. Webb-Murphy, and S.L. Johnston. 2016. Development and validation of a brief measure of psychological resilience: An adaptation of the response to stressful experiences scale. Military Medicine 181(3): 202-208.

DeVellis, R.F. 2017. Scale development: Theory and applications, 4th edn. Los Angeles, CA: Sage Publishing.

Ferketich, S. 1991. Focus on psychometrics. Aspects of item analysis. Research in Nursing \& Health 14(2): 165-168.

Field, A. 2013. Discovering statistics using IBM SPSS statistics. Los Angeles, CA: Sage Publishing.

Flaherty, A.J., M.F. Gaviria, D. Pathak, T. Mitchell, R. Wintrob, J.A. Richman, and S. Birz. 1988. Developing instruments for crosscultural psychiatric research. The Journal of Nervous and Mental Disease 176(5): 260-263.

Henry, J.D., and J.R. Crawford. 2005. The short-form version of the Depression Anxiety Stress Scales (DASS-21): Construct validity 
and normative data in a large non-clinical sample. British Journal of Clinical Psychology 44(2): 227-239.

Iwasa, H., N. Moriyama, Y. Kuroda, C. Nakayama, M. Orui, T. Horiuchi, T. Nakayama, M. Sugita, et al. 2019. Recovery from radiation anxiety and posttraumatic growth among community dwellers after the nuclear disaster in Fukushima. Cogent Psychology 6(1). https://doi.org/https://doi.org/10.1080/ 23311908.2019.1602970.

Javali, S.B., N.V. Gudaganavar, and S.M. Raj. 2011. Effect of varying sample size in estimation of coefficients of internal consistency. WebmedCentral 2(2): Article WMC001649.

Johnson, D.C., M.A. Polusny, C.R. Erbes, D.W. King, L. King, B. Litz, P. Schnurr, and M. Friedman et al. 2011. Development and initial validation of the Response to Stressful Experiences Scale (RSES). Military Medicine 176(2): 161-169.

Jungki, L. 2019. Effects of perceived control upon self-efficacy and satisfaction among healthcare service customers. The Academy of Customer Satisfaction Management 21(2): 79-100.

Kiliç, N., and N. Şimşek. 2019. The effects of psychological first aid training on disaster preparedness perception and self-efficacy. Nurse Education Today 83: Article 104203.

King, L.A., D.W. King, D.S. Vogt, J. Knight, and R.E. Samper. 2006. Deployment risk and resilience inventory: A collection of measures for studying deployment-related experiences of military personnel and veterans. Military Psychology 18(2): 89-120.

Kyriazos, T. 2018. Applied psychometrics: Sample size and sample power considerations in factor analysis (EFA, CFA) and SEM in general. Psychology 9(8): 2207-2230.

Liu, X.S. 2013. Statistical power analysis for the social and behavioral sciences: Basic and advanced techniques. New York: Routledge.

MacCallum, R.C., K.F. Widaman, S. Zhang, and S. Hong. 1999. Sample size in factor analysis. Psychological Methods 4(1): 84-99.

Malik, U.R., N. Atif, F.K. Hashmi, F. Saleem, H. Saeed, M. Islam, M. Jiang, M. Zhao, et al. 2020. Knowledge, attitude, and practices of healthcare professionals on COVID-19 and risk assessment to prevent the epidemic spread: A multicenter cross-sectional study from Punjab, Pakistan. International Journal of Environmental Research and Public Health 17(17): Article 6395.

Mao, X., O.W. Fung, X.Y. Hu, and A.Y. Loke. 2018. Psychological impacts of disaster on rescue workers: A review of the literature. International Journal of Disaster Risk Reduction 27: 602-617.

Mao, X., O.W. Fung, X. Hu, and A.Y. Loke. 2020. Characteristics of resilience among disaster rescue workers: A systematic review. Disaster Medicine and Public Health Preparedness, First View. . https://doi.org/10.1017/dmp.2020.192.

Mao, X., A.Y. Loke, O.W.M. Fung, and X. Hu. 2019. What it takes to be resilient: The views of disaster healthcare rescuers. International Journal of Disaster Risk Reduction 36: Article 101112.

Mao, X., A.Y. Loke, and X. Hu. 2020. Developing a tool for measuring the disaster resilience of healthcare rescuers: A modified Delphi study. Scandinavian Journal of Trauma, Resuscitation and Emergency Medicine 28(1): 1-12.

Mao, X., Z. Wang, X. Hu, and A.Y. Loke. 2020. A scoping review of resilience scales of adults to develop a prototype disaster resilience tool for healthcare rescuers. International Journal of Disaster Risk Reduction 49: Article 101678.

Martin, G., J. Copeland, P. Gates, and S. Gilmour. 2006. The Severity of Dependence Scale (SDS) in an adolescent population of cannabis users: Reliability, validity and diagnostic cut-off. Drug and Alcohol Dependence 83(1): 90-93.

Masten, A.S. 2001. Ordinary magic: Resilience processes in development. American Psychologist 56(3): Article 227.

McEntire, D.A. 2014. Disaster response and recovery: Strategies and tactics for resilience. Hoboken, NJ: John Wiley \& Sons.
Moss, M., V.S. Good, D. Gozal, R. Kleinpell, and C.N. Sessler. 2016. A critical care societies collaborative statement: Burnout syndrome in critical care health-care professionals. A call for action. American Journal of Respiratory and Critical Care Medicine 194(1): 106-113.

Nishi, D., Y. Kawashima, H. Noguchi, M. Usuki, A. Yamashita, Y. Koido, and Y.J. Matsuoka. 2016. Resilience, post-traumatic growth, and work engagement among health care professionals after the Great East Japan Earthquake: A 4-year prospective follow-up study. Journal of Occupational Health 58(4): 347-353.

Nunnally, J. 1978. Psychometric methods. New York: McGraw-Hill.

Pendall, R., K.A. Foster, and M. Cowell. 2010. Resilience and regions: Building understanding of the metaphor. Cambridge Journal of Regions, Economy and Society 3(1): 71-84.

Perrin, M.A., L. DiGrande, K. Wheeler, L. Thorpe, M. Farfel, and R. Brackbill. 2007. Differences in PTSD prevalence and associated risk factors among World Trade Center disaster rescue and recovery workers. American Journal of Psychiatry 164(9): 1385-1394.

Resnick, B., L. Gwyther, and K.A. Roberto. 2011. Resilience in aging. Heidelberg: Springer.

Reyes, A.T., M.A. Andrusyszyn, C. Iwasiw, C. Forchuk, and Y. Babenko-Mould. 2015. Nursing students' understanding and enactment of resilience: A grounded theory study. Journal of Advanced Nursing 71(11): 2622-2633.

Sarker, M.N.I., M.S. Islam, M.E. Huq, G.M. Alam, and M.L. Raihan. 2020. Big data-driven disaster resilience. In Information and communication technologies for humanitarian services, ed. M.N. Islam, 165-185. London: The Institution of Engineering and Technology.

Scuri, S., F. Petrelli, T.T.C. Nguyen, and I. Grappasonni. 2019. Training to improve resilience and coping to monitor PTSD in rescue workers. Journal of Preventive Medicine and Hygiene 60(1): E58-E63.

Shoukri, M.M., M.H. Asyali, and A. Donner. 2004. Sample size requirements for the design of reliability study: Review and new results. Statistical Methods in Medical Research 13(4): 251-271.

Stamm, B.H. 2009. Professional quality of life: Compassion satisfaction and fatigue version 5 (ProQOL). https://proqol.org/. Accessed 2 Apr 2020.

Stein, D.J., W.T. Chiu, I. Hwang, R.C. Kessler, N. Sampson, J. Alonso, G. Borges, E. Bromet, et al. 2010. Cross-national analysis of the associations between traumatic events and suicidal behavior: Findings from the WHO World Mental Health Surveys. PLoS ONE 5(5): Article e10574.

Streiner, D.L., G.R. Norman, and J. Cairney. 2015. Health measurement scales: A practical guide to their development and use. Oxford, UK: Oxford University Press.

Tang, B., Y. Ge, Z. Liu, X. Liu, P. Kang, Y. Liu, and L. Zhang. 2015. Health-related quality of life for medical rescuers one month after Ludian earthquake. Health and Quality of Life Outcomes 13(1): Article 88.

Tominaga, Y., T. Goto, J. Shelby, A. Oshio, D. Nishi, and S. Takahashi. 2020. Secondary trauma and posttraumatic growth among mental health clinicians involved in disaster relief activities following the 2011 Tohoku earthquake and tsunami in Japan. Counselling Psychology Quarterly 33(4): 427-447.

Tsai, J., R. El-Gabalawy, W. Sledge, S.M. Southwick, and R.H. Pietrzak. 2015. Post-traumatic growth among veterans in the USA: Results from the National Health and Resilience in Veterans Study. Psychological Medicine 45(1): 165-179.

UNDRR (United Nations Office for Disaster Risk Reduction). 2019. Global platform preparatory days / World reconstruction conference. https://www.unisdr.org/conference/2019/globalplat form/home. Accessed 18 May 2019 
UNISDR (United Nations International Strategy for Disaster Reduction). 2015. Sendai framework for disaster risk reduction 2015-2030. https://www.unisdr.org/files/43291_sendaiframe workfordrren.pdf. Accessed 15 May 2019.

Wagnild, G.M., and H.M. Young. 1993. Development and psychometric evaluation of the Resilience Scale. Journal of Nursing Measurement 1(2): 165-178.
Zerach, G., Z. Solomon, A. Cohen, and T. Ein-Dor. 2013. PTSD, resilience and posttraumatic growth among ex-prisoners of war and combat veterans. Israel Journal of Psychiatry and Related Sciences 50(2): 91-99. 